\title{
Dynamic Contrast-Enhanced Magnetic Resonance Imaging
}

National Cancer Institute

\section{Source}

National Cancer Institute. Dynamic Contrast-Enhanced Magnetic Resonance Imaging. NCI Thesaurus. Code C62665.

A modification of contrast-enhanced MRI that allows observation of functional properties in addition to structural properties. 